$\begin{array}{ll} & \text { Etnográfica } \\ \text { etnográfica } & \text { Revista do Centro em Rede de Investigação em }\end{array}$

Antropologia

vol. 20 (1) | 2016

Vol. 20 (1)

\title{
Do Ipê Roxo na Cidade Nova: experiência etnográfica e aprendizagem situada
}

\section{Regina Coeli Machado e Silva}

\section{OpenEdition}

\section{Journals}

\section{Edição electrónica}

URL: https://journals.openedition.org/etnografica/4225

DOI: 10.4000/etnografica.4225

ISSN: 2182-2891

\section{Editora}

Centro em Rede de Investigação em Antropologia

\section{Edição impressa}

Data de publição: 1 fevereiro 2016

Paginação: 119-142

ISSN: 0873-6561

\section{Refêrencia eletrónica}

Regina Coeli Machado e Silva, «Do Ipê Roxo na Cidade Nova: experiência etnográfica e aprendizagem situada», Etnográfica [Online], vol. 20 (1) | 2016, posto online no dia 04 março 2016, consultado o 10 fevereiro 2022. URL: http://journals.openedition.org/etnografica/4225 ; DOl: https://doi.org/10.4000/ etnografica. 4225

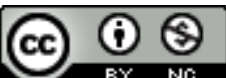

Etnográfica is licensed under a Creative Commons Attribution-NonCommercial 4.0 International License. 


\section{Do Ipê Roxo na Cidade Nova: experiência etnográfica e aprendizagem situada}

\section{Regina Coeli Machado e Silva}

Apresentar reflexões de uma experiência etnográfica centrada em aprendizagens ocorridas por um engajamento assumido em conjunto entre pesquisadores universitários, professores de ensino fundamental e médio, crianças, adolescentes e pais em uma escola pública de Foz do Iguaçu é o objetivo deste artigo. Os dados etnográficos foram construídos durante um programa desenvolvido na escola e mostram que, embora demandada por gestores das políticas educacionais públicas nacionais, essa experiência abriu condições de reflexividade em nossas interações e trouxe implicações éticas, políticas e epistemológicas sobre a aprendizagem em contexto. Partindo da premissa de que a aprendizagem resulta de uma interação social que incorpora as desigualdades sociais e os processos classificatórios e que está embebida na prática, a pesquisa ligou intrinsecamente diversas atividades dos envolvidos, incluiu a escola e o bairro no tempo da memória e do vivido e evidenciou esses espaços como conquistas indissociáveis de um processo de luta simbólica e política em interação com a cidade.

PALAVRAS-CHAVE: aprendizagem, etnografia escolar, antropologia e educação, escola, infância.

About Ipê Roxo in Cidade Nova: ethnographic experience and situated learning - The objective of this article is to present reflections on an ethnographic experience centered on learning occurring through an assumed engagement between university researchers, elementary and middle school teachers, children, adolescents and parents in a public school in Foz do Iguaçu. The ethnographic data were built during a program developed in the school and shows that, though demanded by managers of national public education policy, this experience opened reflexive conditions in our interactions, and brought ethical, political, and epistemological implications regarding learning in context. Based on the premise that learning results in a social interaction which incorporates social inequalities as well as qualifying processes and is embedded in practice, this ethnographic experience intrinsically linked diverse activities of those involved, including the school and the neighborhood as in memory and lived time, and showed these spaces as achievements inseparable from a process of symbolic fight and policy in interaction with the city.

KEYWORDS: learning, educational ethnography, anthropology and education, school, childhood.

SILVA, Regina Coeli Machado e (rcoelims@gmail.com) - Programa de Pós-Graduação Interdisciplinar Sociedade, Cultura e Fronteiras/CELS (Centro de Educação, Letras e Saúde), Unioeste/Universidade Estadual do Oeste do Paraná, Brasil. 


\section{INTRODUÇÃO}

O objetivo deste $\operatorname{artigo~}^{1}$ é apresentar reflexões de uma experiência etnográfica centrada em aprendizagens assumidas em conjunto, envolvendo pesquisadores e estagiários universitários, alunos, professores, pais e responsáveis, em uma escola pública estadual de Foz do Iguaçu, de ensino fundamental e médio. ${ }^{2}$ Embora a afirmação da existência de uma aprendizagem assumida em conjunto suponha um grupo de "aprendizes" ${ }^{3}$ atuando como interlocutores, a experiência nessa escola foi, inicialmente, demandada por agentes de instituições educacionais públicas brasileiras, por meio do Observatório da Educação, um programa de abrangência nacional, operacionalizado localmente. ${ }^{4}$ Esse programa concebe a escola como uma organização integrada, de gestão pública e privada, e se baseia no ideal de transferência de um conhecimento universalizável endereçado a crianças e jovens. O programa tem como pressuposto habilidades cognitivas para aprendizagem fora de contexto - a serem testadas por meio de exames internacionais e nacionais como o Programa Internacional de Avaliação de Alunos (PISA) e a Prova Brasil, que avaliam os índices de aproveitamento escolar dos alunos nas escolas públicas brasileiras, compatibilizados com os países da Organização para a Cooperação e Desenvolvimento Econômico (OCDE). ${ }^{5}$ Assim, condicionado por dados estatísticos sobre os baixos

1 Agradecemos à Capes/Inep pelo financiamento do Observatório de Educação: Núcleo de Pesquisa/Extensão - Formação Continuada em Leitura, Escrita e Oralidade (Santos 2010), bem como o financiamento do projeto "Juventude e Dramas de Moralidade: Dissonâncias nas Práticas de Leitura e de Escrita em Uma Escola de Periferia em Foz do Iguaçu”, pelo MCTI/CNPq/MEC/Capes (Silva 201 1), coordenados respectivamente por Maria Elena Pires Santos e Regina Coeli Machado e Silva. Agradeço igualmente aos professores, alunos e pais pelo trabalho colaborativo, à Antonádia Borges, Diana Milstein e Maria Elena Pires Santos pelos debates instrutivos e aos pareceristas pela leitura atenta e sugestões.

2 No Brasil, a educação pública é organizada em três esferas de competências e gestão: municipal, estadual e federal. A educação básica é competência dos estados e municípios, geralmente dividida entre a educação fundamental, da responsabilidade do município até o $5 .^{\circ}$ ano. O ensino fundamental do $6 .^{\circ}$ ao $9 .^{\circ}$ ano e/ou ensino médio é prioritariamente competência do estado, de acordo com a Lei de Diretrizes Básicas da Educação Nacional (Lei n. ${ }^{\circ}$ 9394, de 20 de dezembro de 1996, Diário Oficial [da República Federativa do Brasil], Brasília, DF, v. 134, n. 248, 23 de dezembro de 1996, seção I).

3 Fiz aqui uma analogia com a expressão "comunidade de conhecedores", de Roy Wagner (2010: 30).

4 "O Observatório da Educação visa ao desenvolvimento de estudos e de pesquisas na área de educação. Lançado em 2006, é implementado pela Coordenação de Aperfeiçoamento de Pessoal de Nível Superior (Capes) e pelo Instituto Nacional de Estudos e Pesquisas Educacionais Anísio Teixeira (Inep), órgãos vinculados ao Ministério da Educação do Brasil (MEC). Tem como objetivo estimular o crescimento da produção acadêmica e a formação de recursos humanos pós-graduados, nos níveis de mestrado e doutorado por meio de financiamento específico. As normas do programa exigem a utilização dos dados estatísticos educacionais produzidos pelo Inep como subsídio ao aprofundamento de estudos sobre a realidade educacional brasileira" ( $<$ http://observatorio.inep.gov.br/o-que-e $>$, última consulta em 17/09/2013).

5 Segundo informações contidas no site, "foi o Inep quem estabeleceu parâmetros técnicos de comparação entre a qualidade dos sistemas de ensino do Brasil com os de países da OCDE. [continua] 
índices de aproveitamento dos alunos de escolas públicas do Brasil, foi esse o ponto de partida da experiência etnográfica em questão. ${ }^{6}$

O programa foi desenvolvido durante três anos, como proposto por Maria Elena Pires Santos (2010), e reuniu professores e pesquisadores da universidade (no momento inicial também gestores, pois coordenadores locais do programa), com formação em Linguística Aplicada e em Antropologia, além de estudantes da pós-graduação e estagiários de licenciatura em Letras. Durante esse período, manteve-se uma média de 20 a 25 professores participantes da escola. No primeiro ano, foram realizados encontros de grupo de estudo interdisciplinar, formados por pedagogos e professores de diferentes disciplinas da escola. ${ }^{7}$ Os temas para estudo eram escolhidos pelo grupo e, nesses encontros, emergiu a proposta dos professores de "construir" a memória do bairro, efetivada como um projeto de pesquisa. Momento de inflexão fundamental, o desenvolvimento do projeto ultrapassou o contexto institucional escolar, incluindo pais dos alunos e moradores do bairro. A efetividade dessa experiência propiciou uma aprendizagem situada, ligou intrinsecamente práticas de todos os envolvidos, manifestou o bairro e a escola como inseparáveis e abriu condições de reflexividade das nossas próprias interações simbólicas e políticas. Todo esse desdobramento trouxe implicações éticas, políticas e epistemológicas para pensar a aprendizagem em termos cognitivos e relacionais.

Ou seja, a referência à OCDE é parâmetro técnico em busca da qualidade, e não um critério externo às políticas públicas educacionais desenvolvidas pelo MEC, no âmbito da realidade brasileira" (< http://portal.inep.gov.br/web/portal-ideb/o-que-sao-as-metas > , última consulta em 26/04/2015).

6 De acordo com dados fornecidos pelo Instituto Nacional de Estudos e Pesquisas Educacionais Anísio Teixeira (Inep), o índice de desenvolvimento da educação básica (IDEB) do Brasil tem ficado muito aquém daquele atingido pelos países da Organização para a Cooperação e Desenvolvimento Econômico (OCDE). O IDEB é um indicador de qualidade educacional que combina informações de desempenho em exames padronizados (Prova Brasil ou Saeb) - obtido pelos estudantes ao final das etapas do ensino fundamental $\left(5 .^{\circ}\right.$ e $9 .^{\circ}$ ano e $3 .^{\circ}$ ano do ensino médio) - com informações sobre rendimento escolar (aprovação). A média nacional registrada em 2009, para os anos iniciais do ensino fundamental público ficou em 4,4 e para os anos finais do ensino médio público ficou em 3,7. Embora esses índices tenham superado as metas propostas pelo Inep para o referido ano (respectivamente 4,0 e 3,4), estão longe dos índices dos países da OCDE, que atingem em média 6,0 (Santos 2010). Em 2013, o país ultrapassou em 0,3 pontos as metas previstas para os anos iniciais ( $1 .^{\circ}$ ao $5 .^{\circ}$ ano) do ensino fundamental. O IDEB nacional nessa etapa ficou em 5,2, enquanto em 2011 havia sido de 5,0. Nos anos finais (6. ${ }^{\circ}$ ao 9. ${ }^{\circ}$ ano) do ensino fundamental, o IDEB nacional cresceu de 4,1 em 2011 para 4,2 em 2013 . No ensino médio se manteve em 3,7 (dados disponíveis em < http://portal.inep.gov.br >, última consulta em 22/09/2014).

7 Entre os professores da escola, havia seis bolsistas (três de Língua Portuguesa, um de Geografia, um de Matemática e um de Ciências); entre os alunos, cinco bolsistas e uma voluntária dos cursos de Letras da Unioeste, as quais desenvolveram seus estágios curriculares supervisionados juntamente com os professores da escola; entre os professores da universidade, havia quatro professoras, duas do mestrado interdisciplinar em Sociedade, Cultura e Fronteiras (Unioeste); uma orientadora educacional e demais professores, de diferentes áreas, do colégio. 
As referências analíticas mais específicas para a compreensão dessa aprendizagem partem da ontologia social da cognição, pressupondo a oralidade, a leitura e a escrita como práticas sociais específicas, intrínsecas à vida relacional. Para desenvolver esse argumento, na primeira seção do artigo contextualizo os debates da antropologia implicados na cognição, empreendidos por suas articulações com a educação, a infância e a escola. Trata-se de uma contextualização que, ao inserir esses debates no movimento de refinamento teórico recente da disciplina, igualmente pretende realçar as contribuições analíticas recentes sobre a cognição e suas relações com a aprendizagem como um recurso epistemológico e metodológico para transpor certos determinismos sociológicos quando nos indagamos sobre diferentes problemas envolvidos na educação. Sob esse enquadramento, apresento uma proposta analítica de compreensão da aprendizagem como parte intrínseca de um sistema cognitivo construído na interação social. Na segunda seção, aponto os caminhos que permitiram nossa inserção na escola, com suas particularidades; na terceira, descrevo o desenvolvimento e os resultados desse processo etnográfico com envolvimento de todos e no qual formamos uma "comunidade de aprendizes". Finalmente, teço considerações a respeito das implicações teóricas, políticas e epistemológicas da experiência aqui apresentada.

\section{A APRENDIZAGEM COMO MODO DE PARTICIPAÇÃO EM PRÁTICAS SOCIAIS}

Pressupor que o sistema cognitivo é construído na interação social nos coloca no centro das questões abordadas pela antropologia da cognição proposta por Jean Lave (1988; Lave e Wenger 1991). Partindo de uma teoria mais abrangente sobre a prática social, essa autora define a aprendizagem como atividade situada no processo de pensamento, com implicações para nossas concepções sobre a infância e sobre a educação, fenômenos aí correlacionados. Embora correlacionados, eles circunscrevem subcampos na antropologia, com problemas analíticos específicos, de modo que podemos identificar subcampos reconhecidos como o das relações entre antropologia e educação, o da antropologia da criança e o da antropologia cognitiva. ${ }^{8}$ Enquanto o interesse da antropologia na educação ou no ensino formal tenha sido pouco enfatizado na história

8 Gusmão (1997), por exemplo, enfatizou as origens do diálogo entre a antropologia e a educação, e explicita os interesses de alguns antropólogos na questão educacional, a exemplo de Boas, Ruth Benedict e Margaret Mead. Esse diálogo é revisitado por Dauster (2004). A antropologia da criança tem pressupostos teórico-metodológicos mais específicos (Cohn 2000, 2005; Pires 2010), enquanto a antropologia cognitiva tem um campo de interesse bem maior, pois recentemente tem na aprendizagem um foco de interesse importante, ao tentar responder como o conhecimento humano é construído, aprendido, mantido e reformulado (Toren 1993, 2012; Ingold 1991, 1993, 2002; Lave 1988, 1996, 2011). 
da antropologia, a preocupação com a socialização e a transmissão da cultura, ao contrário, foi importante não só pela premissa da especificidade ontológica social do pensamento, mas também pela aprendizagem diretamente ligada às preocupações com a cognição, a como se processa o conhecimento e como se constroem modelos de compreensão das sociedades e suas relações. Recentemente, esses subcampos da antropologia vêm se interpenetrando cada vez mais, colocando em primeiro plano a aprendizagem, objeto congruente e constitutivo da autocrítica da antropologia que, nos últimos anos, trouxe o retorno do sujeito, da agência e da prática, como apontaram Ortner (1984) e Viveiros de Castro (2002). De modo análogo e complementar, os desdobramentos dessa autocrítica tiveram como efeito colocar sob suspeita o alcance explicativo de conceitos sociológicos como o de cultura e de sociedade (a exemplo de Abu-Lughod 1999; Stolke 1995; Strathern 2014), exigindo mais refinamentos na análise. Trata-se de formulações propiciadoras de um debate instigante que evidencia o comprometimento com a relativização dos próprios fundamentos da antropologia, cujo desafio interpretativo continua aberto.

Meu interesse ao centrar a reflexão no processo de aprendizagem é, justamente, explorar o desafio interpretativo de conceber a aprendizagem como prática social que ultrapassa o contexto institucional escolar, mesmo estando situada e localizada em uma escola. Isto é, o enfoque na cognição construída na interação nos permite ir além das ideias de que os processos educacionais supostos na escola são modos de existência reproduzindo a si mesmos, pela reprodução legítima das desigualdades e das distinções sociais, ao modo de Bourdieu (1982), ou formas de poder ou resistência imanentes a essa reprodução (Foucault 1988, 1999). Tais perspectivas analíticas, mesmo divergentes, compartilham a suposição da especificidade ontológica do social, de tal modo que o processo cognitivo é visto como fenômeno histórico, social e culturalmente situado, tanto em termos políticos (Bourdieu 1982; Lahire 2003), quanto na prática social cotidiana (Lave 1988, 1996; Lave e Wenger 1991; Toren 1993, 2003). Isso implica atenção ao modo como jovens, crianças e adultos constituímos nosso conhecimento no mundo, como o processamos e para qual direção movimentamos a aprendizagem.

Essa atenção ao modo como constituímos nosso conhecimento é também um recurso epistemológico e metodológico para transpor determinismos sociológicos dos quais às vezes participamos quando nos indagamos sobre os diferentes problemas envolvidos na educação, perceptíveis desde as promessas de "formar cidadão" e promover a "emancipação humana" até as políticas públicas de educação no país. ${ }^{9}$ Como apontou Lahire (2003), as teorias da

9 Uma contribuição importante para acompanhar, historicamente, as tentativas de ultrapassar determinismos sociológicos, quando se pensa na educação no Brasil, pode ser encontrada em Helena Bomeny (2001). Com o objetivo de escrever a biografia de Darcy Ribeiro, ela toma como eixo [continua] 
reprodução social colocaram "a escola no cerne dos processos de reprodução das desigualdades sociais, por um lado, e num espaço político que tem fé no papel democrático da escola, por outro. Ao analisarem as funções sociais da escola a partir da questão da igualdade e da desigualdade das chances, os sociólogos [...] contribuíram para a construção social e a manutenção de um espaço político fundado sobre a crença em valores de igualdade" (Lahire 2003: 987). Se esse princípio da igualdade de chances pode ser decifrado e criticado como um discurso que justifica as funções da escola, obscurecendo o fato de que ela pode constituir um dos fatores do surgimento e da permanência de mecanismos de seleção social (pelo diploma e acesso às posições profissionais privilegiadas), não seria porque esse modo de pensar deixa de fora a inescapável relação com as práticas sociais dos alunos no contexto em que elas se desenvolvem, assim reiterando a legitimidade da cultura escolar e de todo o sistema de oposições apontado por Bourdieu (1979)? ${ }^{10}$

Outro efeito da teorização do ensino e da aprendizagem que pode ser observado nas teorias da reprodução social aparece nas propostas da antropologia da educação norte-americana, criticadas por McDermott e Varenne (1995). Esses autores evidenciaram um tipo de determinismo social anterior à escola, pois as crianças e os jovens são vistos como parte de grupos socialmente desiguais ou de uma minoria cultural, condições limitadoras da aprendizagem. Trata-se de um senso comum social e sociológico que atribui as dificuldades de aprendizagem à privação (pobreza) e à diferença cultural, de modo que a escola pode tornar-se uma forma de honrar a vida daqueles que foram e são impedidos ou tiveram dificuldades para nela permanecer. Ocorre então uma insuspeita e delicada tensão entre essas duas abordagens (a da pobreza e a da diferença) porque ser pobre e destituído pode ser uma das formas comuns de existir dentro de uma estrutura social, no primeiro caso, e de fazer parte da cultura, no segundo. O contexto e a cultura tornam-se empecilhos para os esforços para ultrapassar as dificuldades de aprendizagem por parte dos professores, enredados por essas racionalizações que subscrevem a aprendizagem à desigualdade e à diferença na sociedade, reiterando, assim, a reprodução social das desigualdades. Em uma direção oposta, mas produzindo as mesmas consequências, está, primeiro, a poderosa e multissituada produção de identidades na escola como comunidades de prática nos EUA, que pode resultar, por exemplo, na produção da racialização, como mostrou Jean Lave (1996). Segundo, mas igualmente poderosa em seus efeitos, a produção de divisões de classe e da desigualdade

[continuação] condutor os debates internos sobre a relação da educação com a sociedade no pensamento sociológico brasileiro e o importante papel dos participantes nesses debates para a construção e implementação de instituições educacionais para o Estado-nação, muitas delas operantes até hoje, como o Inep e a Capes.

10 Trata-se da hierarquização de obras culturais em "nobres" e "respeitáveis" em oposição a outras consideradas "vulgares", "comuns", etc. 
de gêneros. Em analogia com os aprendizes de alfaiate da Libéria que a autora estudou, as crianças e os jovens norte-americanos estão aprendendo, na prática, as divisões sociais e as diferenças de gênero da formação social na qual eles vivem suas vidas (Lave 1996).

As abordagens da escola que a concebem como um modo de reprodução social, embora analiticamente diferentes mas próximas em suas consequências, têm também em comum um postulado implícito, que é a separação entre as crianças que devem aprender e os adultos que devem ensinar, razão pela qual a aprendizagem é entendida como parte do processo de socialização e de inculcação cultural. Uma abordagem antropológica consistente com a ontologia social da cognição não concebe as crianças e os jovens como grupos separados do mundo adulto, mas como interlocutores de um processo de aprendizagem em suas relações. Como afirma Christina Toren (1993), a infância não é uma etapa da vida isolada da vida adulta, mas se constitui como um espaço de intersubjetividades de modo que o processo cognitivo depende da inserção da criança no mundo e do conhecimento sobre ele obtido por meio das relações sociais que as crianças estabelecem com outros membros da comunidade (outras crianças e adultos). Essa autora chama a atenção para a falta de interesse dos antropólogos contemporâneos pelas crianças, cuja raiz pode estar, segundo ela, na ideia de que o fim da socialização é conhecido (Toren 1993). É a falta de atenção à criança como interlocutora entre adultos que induz à baixa consideração das experiências intersubjetivas de aprendizagem, como vem chamando a atenção Jean Lave, ao supor que a socialização é um processo contínuo. Essa autora propõe uma antropologia cognitiva da aprendizagem como um problema relacional na vida social, cujos participantes interagem uns com os outros como condição e precondição de sua existência, motivo pelo qual não faz sentido pensá-la como uma questão que diz respeito apenas às crianças e aos jovens.

Segundo Lave (1988: 1), ${ }^{11}$ a cognição é um fenômeno social complexo, que pode ser observado na prática cotidiana, sendo distribuída entre mente, corpo, atividade e ambientes culturalmente organizados. A cognição é um nexus de relações entre a mente em ação e o mundo no qual ela atua. Como consequência, a aprendizagem é histórica e contextual. É um aspecto das atividades em que as pessoas são constituídas e se constituem em comunidades de práticas (Lave 2011: 19). ${ }^{12}$ Como tentarei evidenciar, a aprendizagem é

11 " [...] what we call cognition is in fact a complex social phenomenon. [...] 'Cognition' observed in everyday practice is distributed - stretched over, not divided among - mind, body, activity and culturally organized settings (which include other actors) $[\ldots]$ for pursuing explanations of cognition as nexus of relations between the mind at work and the world in which it works" (Lave 1988: 1).

12 Christina Toren (2012) define a cognição considerando a mente como uma função do ser humano integral em relações intersubjetivas com outros no mundo circundante, o que diz respeito aos humanos enquanto seres viventes e autopoiéticos. 
situada, ${ }^{13}$ está embebida na prática e resulta de uma interação social de componentes que incorporam as desigualdades sociais, os processos classificatórios e os comportamentos adquiridos.

Conceber a aprendizagem como uma maneira de "estar" no mundo e como compreensão pela prática supõe igualmente uma compreensão da linguagem como prática sócio-historicamente situada (Bakhtin 2003) e tem inúmeras repercussões para o campo da linguística aplicada, da sociolinguística e para os educadores em geral. Moita Lopes e Rojo (2004) demonstram como é importante pensar na natureza construcionista, sociointeracional e situada da linguagem, trazendo à tona o fato de que a linguagem não ocorre em um vácuo social. Portanto, segundo eles, textos orais e escritos não têm sentidos em si mesmos, do mesmo modo que crianças e jovens aí são compreendidos como sujeitos ativos, interagindo com esses textos como práticas sociais.

Tais pressupostos teóricos sobre a aprendizagem, trazidos por Jean Lave, e sobre a linguagem, trazidos por Bakhtin, como se pode observar, não presumem um processo de segregação ou de isolamento da educação escolar da criança, modo pelo qual nossas escolas estão organizadas, e isso nos devolve ao ponto de partida da nossa experiência etnográfica. Como propôs Qvortrup (2010: 640), a escolarização da infância é também um resultado das demandas provenientes de uma economia e de um sistema de governo em transformação, sob determinadas circunstâncias, como as das políticas públicas nacionais. Em outras palavras, a infância, em termos estruturais, assume formas diferentes como resultado das transformações sociais (Qvortrup 2010: 640-641).

Contudo, se a escolarização da infância é parte de mudanças que aconteceram devido às demandas na economia e no sistema de governo, isso não a torna menos "comunidade de prática", isto é, expressiva das interações entre grupos posicionados diferentemente no contexto. ${ }^{14}$ Ao contrário, como aqui pretendo mostrar, a interação tornou-se condição da nossa experiência na escola: ao responder a essas demandas como pesquisadores, convertendo-nos no mesmo movimento em gestores de um programa nacional, confrontamo-nos, como interlocutores, com outros modos de enfrentar os mesmos problemas, com interesses e desejos divergentes; com as particularidades de alunos, moradores e professores em situações nas quais somos também participantes. É como interlocutora, procurando reter o momento do diálogo e da conversa que, primeiro, apresentarei a escola e como chegamos a ela. Depois, menciono as condições de possibilidade da experiência etnográfica implicada na aprendizagem,

13 " $[\ldots]$ situated activity is anything but a simple concept; it is a general theoretical perspective that generates interconnected theories of perception, cognition, language, teaming, agency, the social world, and their interelations" (Lave e Wenger 1991: 66).

14 "Comunidade de prática" tem aqui um significado abrangente ao reunir atores sociais em contextos singulares específicos. Hoje essa expressão tende a ser identificada como uma estratégia para promover a aprendizagem em organizações, de um modo geral. 
com ênfase nas considerações mais significativas que resultaram dessa experiência e evidenciando um evento aglutinador que "desentranhou" a escola de si mesma para abranger o bairro e a cidade.

\section{CONDUZIDOS PELO OBSERVATÓRIO DA EDUCAÇÃO PARA A ESCOLA}

Inicio situando a escola onde ocorreu essa experiência. Localizada no bairro Cidade Nova, periférico à cidade de Foz do Iguaçu, na fronteira do Brasil com o Paraguai e a Argentina, é uma instituição estadual que atende alunos do $6 .^{\circ}$ ao $9 .^{\circ}$ ano do ensino fundamental e do ensino médio. O bairro foi criado por meio de uma disputa com o poder político local durante um processo de desapropriação urbana ordenada pela Prefeitura Municipal. Os caminhos que nos levaram à escola são os das políticas públicas que financiam programas para escolas com baixa avaliação no IDEB (índice de desenvolvimento da educação básica),$^{15}$ dentre eles o Observatório da Educação, coordenado nacionalmente pelo Ministério de Educação (MEC) e pela Coordenação de Aperfeiçoamento de Pessoal de Nível Superior (Capes). As políticas de educação no Brasil avançaram depois da Constituição de 1988 e da aprovação das diretrizes a ela direcionadas. Embora com avanços para a educação inclusiva e democratização do acesso, essas políticas vêm afirmando as "parcerias" com os setores público e privado ${ }^{16}$ e penetrando, de forma ampla, nas instituições educativas públicas, ${ }^{17}$ abrangendo desde propostas para o conteúdo do conhecimento até os métodos para sua produção ou socialização. Paralelamente, a ênfase na avaliação verificada no Plano Nacional de Educação para o decênio 201 1-2020 induz as administrações estaduais e municipais a atentarem para esses parâmetros, descentralizando as ações nas quais se situa nossa experiência etnográfica.

15 O IDEB observado, nessa escola, foi de 3,4 para 2009 e 201 l, e 3,7 em 2013 (dados disponíveis em < http://ideb.gov.br/resultado > (última consulta em 26/04/2015).

16 Robertson e Verger (2012) analisam o desenvolvimento global da rápida expansão das parecerias público-privadas como um projeto mais amplo de reconstituição da educação pública no âmbito do setor de serviços, do mesmo modo que Silvana A. Souza (2001, 2009, 2013) vem estudando esse tema no Brasil.

17 Tais políticas estão inseridas no essencial de uma política macroeconômica que visa à ampliação de políticas direcionadas à grande parte da população que vive abaixo da linha da pobreza ou em um nível elementar de sobrevivência e consumo. Trata-se não apenas da realização de políticas compensatórias para a baixa distribuição de renda, como é o Programa Bolsa Família, mas do acesso diferenciado e intenso ao crédito para aquisição de casa própria e a bens de consumo, a programas de acesso à energia etc. No plano do financiamento registra-se a criação do Fundo de Manutenção e Desenvolvimento da Educação Básica e de Valorização dos Profissionais da Educação (Fundeb). Outro aspecto diferenciado, ainda que em termos muitíssimo baixos, é a fixação do piso nacional para o magistério da educação básica, uma conquista histórica do magistério nacional (Oliveira 2011). Aprovado por lei federal, o piso nacional é um valor de salário a ser pago igualmente a todos os professores no Brasil, mas enfrenta dificuldades de implementação. 
As diretrizes do Observatório da Educação entendem a educação como uma realidade inconteste, passível de ser "fortalecida", "ampliada" e instrumentalizada por meio de produções acadêmicas, da formação de recursos humanos (docentes, gestores, avaliadores) e da criação e manutenção de programas interdisciplinares. Simultaneamente, elas visam a um sistema educacional eficiente para o ensino fundamental e médio que acompanhe os padrões de avaliação nacional e internacional, como o PISA e a Prova Brasil antes mencionados.

Conduzido por essas referências, o programa Observatório da Educação, proposto pela coordenação local (professores de um mestrado interdisciplinar e da graduação em Letras), foi iniciado em 2011 e tinha como objetivo a formação de professores do ensino fundamental e médio do Colégio Estadual Ipê Roxo, em Foz do Iguaçu. Integrando a pesquisa, o ensino e a extensão, o programa iniciou ministrando minicursos e organizando grupos de estudos, cujos temas eram decididos conjuntamente. Paralelamente ocorriam atividades de pesquisa dos docentes universitários e estágios da graduação. Em seu início, o grupo era constituído por professores da escola, e por professores, estudantes e estagiários de graduação e pós-graduação da universidade. Depois, quando nos tornamos mais próximos e menos intrusos, e à medida que o trabalho se desenvolvia, alunos, pais e moradores do bairro integraram as atividades.

Por causa dos caminhos que nos conduziram à escola, encontramos as dificuldades comuns de qualquer entrada no campo etnográfico e entre elas estava a relutância, por parte dos professores, em participar do programa. Tal relutância era justificada pela aceitação do fracasso escolar como um dado aceito e incontestável, independentemente deles mesmos como professores, que assim reiteravam o senso comum sociológico das teorias da reprodução social da desigualdade social e das diferenças culturais, contra eles mesmos. Uma das razões para isso pode ser encontrada nas profundas ressonâncias das ideias associadas à localização da escola em um bairro periférico. Isto é, o bairro é caracterizado por moradores de Foz do Iguaçu como perigoso, de um ponto de vista exterior e estigmatizante, percepção advinda da construção ativa e persistente de um processo de exclusão social, cristalizada em identificações negativas. No entanto, para os primeiros moradores, a denominação Cidade Nova caracterizava os sonhos e a esperança de "uma vida nova e melhor". ${ }^{18}$ Ele foi criado em 1998 por meio de um programa de "desfavelamento" da região central da cidade. Inicialmente, a prefeitura pretendia instalar as famílias em uma vila rural distante, mas um processo de mobilização e negociação desses moradores com os representantes da prefeitura e do governo estadual fez com que $\mathrm{o}$ assentamento fosse transferido para o local atual.

18 A construção do bairro Cidade Nova teve início em 1998 e só em 1999 os primeiros moradores tomaram posse de suas casas. 
O bairro cresceu e, longe do centro da cidade, não tinha transporte público adequado para viabilizar o deslocamento de jovens e crianças para a escola. Foi então criada pelo governo estadual a escola de ensino fundamental e médio, em 2002, cujo nome, Ipê Roxo, ao contrário dos da maioria da cidade que têm nomes de personalidades públicas ou artísticas, foi uma homenagem à árvore que é símbolo de Foz do Iguaçu.

O sonho realizado de ter casa própria está nos arquivos de matrícula da escola. Em um levantamento aleatório de dados de 60 alunos, observou-se que 50 residem em casa própria, seis em casa cedida e três em casa alugada. Nas fichas de matrícula também consta informação sobre a renda familiar e, desse total, 38 alunos têm renda familiar de até um salário mínimo; 20, de um a três; e dois têm renda familiar acima de três salários mínimos.

Buscar manter a distância o bairro e seus moradores, contudo, pode ser resultado de um desdobramento que envolve a cidade geopoliticamente, como vêm mostrando pesquisadores por meio do estudo de vários temas que a afetam em função de sua posição geográfica (cf. Catta 2011; Cardin 2011; Santos 2012; Albuquerque 2010). Trata-se de uma experiência coletiva singular, por a cidade estar localizada na fronteira entre três países, mas particularmente vivida pelo bairro, associado às atividades dos moradores envolvidos com a zona de livre comércio com o Paraguai. Assim, apesar de dispor de uma boa infraestrutura urbana, com avenidas largas, ruas com calçamento, iluminação e todos os serviços básicos de atendimento à comunidade - como disse um dos moradores, "só faltam uma loja lotérica para fazer pagamentos e um posto de gasolina" -, o bairro continua sendo percebido como perigoso, tanto pelo passado de seus moradores vivido em "favela" quanto por ser identificado como um lugar de atividades "ilícitas", isto é, ligadas ao contrabando de mercadorias no intenso comércio transfronteiriço, e principalmente com Ciudad del Este, onde parte dos moradores do bairro encontra fonte de subsistência, com o transporte ilegal de mercadorias. As mulheres frequentemente trabalham como faxineiras, domésticas e comerciárias e há também ocupações temporárias no setor de serviços turísticos, porque as Cataratas do Iguaçu fazem da cidade um dos polos de atração turística mais importantes no país. Assim, pode-se dizer que há falta de emprego, mas não falta de atividade remunerada, mesmo que incerta e precária. Recentemente, por causa da proximidade com o Paraguai, o bairro tem recebido famílias de "brasiguaios" expulsos pelos conflitos e lutas pela posse da terra nesse país. ${ }^{19}$

Do ponto de vista dos professores, expresso no documento da escola denominado Projeto Político Pedagógico (PPP 2002) - no qual eles expõem as intenções políticas e programáticas do ensino -, por causa da localização, não apenas social, mas também simbólica do bairro, a escola possui uma alta rotatividade

19 "Brasiguaios" são brasileiros e seus descendentes que se estabeleceram no Paraguai em áreas de fronteira com o Brasil. 
de professores e pedagogos. Como ouvimos durante uma reunião, ser professor no Ipê Roxo significa ser "rebaixado" na carreira. Isso não impede, contudo, que todos, inclusive funcionários e colaboradores diretos e indiretos, estejam integrados para "fazer valer a missão da escola". O Projeto Político Pedagógico reitera as consequências desse "isolamento" simbólico do bairro, feito da história do "desfavelamento" e percebido pelos moradores da cidade como um lugar perigoso, de atividades ilícitas e até mesmo de descontrole social, imagens comumente associadas às fronteiras geopolíticas. $\mathrm{O}$ mesmo documento descreve uma pesquisa feita no colégio, cujo resultado apontou que "a maioria dos alunos ficam sozinhos em casa, sem um responsável para acompanhar e cobrar tarefas escolares. $\mathrm{Na}$ maioria das vezes, por estarem sozinhos acabam se envolvendo com más companhias e até mesmo se envolvendo em atividades ilícitas. E assim, seu desenvolvimento e a sua formação acabam sendo prejudicados" (PPP 2002). Parte dessa constatação provém de uma percepção comum, reiterada pelos professores em diferentes momentos, de que as famílias não só deixam os filhos sozinhos, como também são desestruturadas e, por isso, não constituem referências de educação e de disciplina. ${ }^{20}$ No levantamento feito nas fichas de matrícula, acima referido, no campo do formulário onde se deve indicar o responsável pelo aluno, dos 60 alunos, 40 têm como responsável a mãe, 11 deles têm como responsável o pai e 9 têm como responsáveis seus avós ou outros. No Projeto Político Pedagógico lê-se a descrição do perfil do bairro como carente e vulnerável, estando os alunos em situações de risco. A escola é vista como um ponto para onde convergem as problemáticas familiares, pois os pais delegam a ela a responsabilidade de educar os seus filhos, na percepção dos professores e pedagogos, expressa no documento (PPP 2002). Tal situação interfere de forma direta no processo de aprendizagem, não só pela adoção implícita daquele senso comum sociológico que vincula as dificuldades de aprendizagem à privação e à cultura, que comprometem a prática pedagógica, mas também pela falta de acompanhamento da vida escolar por parte das famílias. Tudo isso, segundo o documento, influencia nesta escola os grandes índices de reprovação e evasão escolar. Segundo os professores, há casos de alunos que frequentam a escola refazendo a mesma série por até três anos consecutivos, com graves problemas de adaptação e de indisciplina na sala de aula.

Diante desses "problemas sociais", categoria que sintetiza, nesse campo etnográfico, as diversas causas para a evasão, a reprovação escolar e o baixo índice de avaliação dos alunos nos exames nacionais, como os professores tentam resolver a equação que subscreve a aprendizagem a esse contexto específico? Como enfrentam o dilema das contradições trazidas por critérios universalizantes que pressupõem um conhecimento abstrato e geral, e a resolução de 
problemas cognitivos nesse processo de aprendizagem condicionado pelas circunstâncias do bairro?

Não é por acaso que o bairro, durante a pesquisa etnográfica, foi objeto de uma proposta de construção da sua memória feita pelos professores - por sua história e por sua posição no espaço urbano e mantida a distância simbolicamente pelos moradores de Foz do Iguaçu, que impõe a estes uma permanente indignidade por esses princípios de diferenciação social, buscando mantê-los afastados de toda forma de legitimidade social em uma série de domínios. Essa proposta constituiu-se em um ponto de inflexão importante, porque acabou se revelando como um dos modos possíveis pelos quais professores, alunos, moradores e pesquisadores passamos a nos ver como indissociáveis desse processo de luta simbólica e política, participantes das arenas envolvidas no processo de classificação e de diferenciação social, dentro do qual a escola é parte inseparável. A proposta de "construir" a memória do bairro, identificada como "Projeto Memória”, revelou-se uma experiência etnográfica compartilhada, dando lugar a uma aprendizagem singular e situada.

\section{O PROJETO MEMÓRIA: UMA EXPERIÊNCIA ETNOGRÁFICA COMPARTILHADA COMO APRENDIZAGEM}

A proposta feita pelos professores durante os grupos de discussão, que depois passou a ser identificada por todos como Projeto Memória, configurou-se em um ponto de inflexão fundamental, redirecionando nossa experiência etnográfica e nos tornando uma "comunidade de conhecedores" e uma "comunidade de prática”. Atuando como princípio e conteúdo da efetividade da aprendizagem, o desenvolvimento do Projeto Memória ligou intrinsecamente diversas atividades de professores, alunos, pais, moradores e pesquisadores, incluiu o bairro e a escola no tempo da memória e do vivido nas interações de todos os agentes envolvidos. Como foi possível a efetividade da aprendizagem se fazer como experiência coletiva?

É importante mencionar que a proposta do Projeto Memória definiu-se pelos professores da escola depois de encontros realizados uma vez por mês, durante um ano, sob a forma de grupos de trabalhos para a formação de professores. Do ponto de vista da aprendizagem, adotou-se como estratégia téorico-metodológica, primeiro, a abordagem interdisciplinar, unindo professores de diferentes áreas do conhecimento em atividades conjuntas complementares, para evidenciar as inter-relações constitutivas desses conhecimentos e, depois, inspirados inicialmente nas teorias de Bakhtin para "construir" a memória do bairro, os professores da escola sugeriram os gêneros discursivos como propôs esse autor. Gêneros de discurso são "tipos relativamente estáveis de enunciados" (Bakhtin 2003: 279), que incluem desde os diálogos cotidianos até as enunciações da vida pública, institucional, artística, científica e filosófica. 
Os gêneros não são adquiridos em manuais, mas nos processos interativos. Para começar o levantamento do inventário da história do bairro e da escola, o relato, o "causo", a entrevista, a receita culinária, o convite, a carta de agradecimento, a literatura de cordel, a peça de teatro, a autobiografia e biografia efetivaram-se como práticas de leitura, escrita e oralidade, desenvolvidas conjuntamente pelos professores das diferentes disciplinas, considerando o caráter sociocomunicativo desses diferentes gêneros do discurso.

Para iniciar a história do bairro, alunos dos $7 .^{\circ}, 8 .^{\circ}$ e $9 .^{\circ}$ anos do ensino fundamental e do $1 .^{\circ}$ ano do ensino médio, com os professores dessas séries, buscaram, junto aos moradores, documentos, artigos de jornais, fotos que registravam diferentes momentos da construção do bairro e da construção da escola. Trouxeram fotos antigas, retratando o terreno vazio onde posteriormente foram construídas as casas e o colégio. Fizeram um levantamento dos moradores mais antigos, bem como daqueles que tiveram um papel de liderança nas reivindicações por melhorias no bairro, e identificaram os músicos e os poetas, para serem posteriormente entrevistados. Percorreram as ruas do bairro, para registrar, em fotos, o espaço ocupado pelo bairro e se surpreenderam com lugares que não conheciam, embora o bairro seja relativamente pequeno e recente. Nesse processo de "reconhecimento" do lugar da moradia, encontraram um jornal em funcionamento, uma biblioteca pública organizada e mantida por voluntários do próprio bairro, um grupo de hap, o Hap Cidade Nova, do qual participam alguns alunos do colégio.

Cada etapa dessa experiência de pesquisa conjunta era retomada e compartilhada na sala de aula e nas reuniões. Com a utilização da "TV Pendrive" ${ }^{21}$ na sala de aula, identificavam suas casas, as casas dos seus colegas, o comércio, as igrejas, as escolas, a creche, o "postinho" (o posto de atendimento à saúde), o local de funcionamento da Pastoral da Criança onde muitos fizeram a catequese, o clube esportivo e a casinha sobre a árvore de que eles tanto gostavam. Compartilhar os "achados" foi reapropriar-se do bairro por meio de uma identificação ao mesmo tempo próxima e distante. Um dos alunos perguntou "como conseguimos fazer tudo ficar tão bonito?" A professora comentou que, provavelmente, todos estavam "começando a ver o que não enxergavam. Se, no início a maioria dos alunos se mostravam reticentes e desmotivados, depois passaram a se envolver cada vez mais e, nas pesquisas seguintes, saíam na frente, conversando com moradores sobre o projeto, pedindo permissão para fotografar e registrar todos os momentos, sendo bem-recebidos por eles. A partir

21 "TV Pendrive" é um projeto da Secretaria de Educação do Estado do Paraná, que instalou um televisor de cor laranja nas salas de aula, com entrada para cartão de memória. O objetivo desse projeto é proporcionar aos professores recursos que podem complementar e apoiar o processo de ensino-aprendizagem. Eles podem salvar, em um pen drive, objetos de aprendizagem disponíveis no Portal Dia-a-dia Educação do estado do Paraná e utilizá-los nas aulas (informação em $<$ http://www.gestaoescolar.diaadia.pr.gov.br >, última consulta em 21/10/2014). 
desse envolvimento intenso na experiência, viam-se como agentes e coconstrutores da própria história, (re)conhecendo o processo de construção coletiva da memória do bairro e da escola como conquistas inseparáveis de todos.

Esse processo possibilitou a efetividade da aprendizagem de forma social e culturalmente situada na prática cotidiana, obtida pela coconstrução do conhecimento por meio dos gêneros discursivos. Apresentarei aqui apenas dois dos gêneros discursivos em nossa experiência etnográfica. O gênero autobiografia, elaborado por meio de redações dos alunos, por dar uma ideia de parte da experiência coletiva vivida no bairro, e o gênero teatro. A escrita, preparação e encenação da peça de teatro foi tanto uma forma sintética de totalizar a história do bairro e da escola, quanto condensação de diversos gêneros de discursos utilizados para a construção do Projeto Memória. Ressalto, porém, que todos os gêneros discursivos propiciaram formas de autoentendimento e de reflexividade dos alunos e de todos os participantes. O gênero discursivo receita culinária, por exemplo, embora estivesse ligado à preocupação com as medidas matemáticas, revelou-se como uma prática significativa. Redigir a receita permitiu ver, de forma reflexiva, os hábitos alimentares como veículos de emoção, pois o comportamento relativo à comida estava diretamente ligado à identidade de cada aluno, evidenciando a afetividade de suas relações no ambiente familiar: as receitas estavam intimamente ligadas aos pratos preferidos pelos alunos, às habilidades especiais de um dos membros da família em fazer um prato específico, às datas comemorativas, quando são feitos pratos especiais, como aniversários, Natal e Dia dos Pais. As receitas explicitaram o ato de comer como sentimento relacional e duradouro, mostrando as relações afetivas dos alunos em seu convívio mais íntimo.

O convite feito aos jovens pelos professores para escreverem a autobiografia causou estranhamento porque esses gêneros, segundo eles, são apenas para "pessoas importantes". Uma das alunas argumentou não ser "muito velha por isso não tenho muitas histórias para contar" (Indianara). A autobiografia revelou-se um dos mais pregnantes dentre os outros para apreender a aprendizagem como situada e como comunidade de prática. Privilegio aqui 21 autobiografias feitas por alunos das turmas de $8 .^{\circ}$ e $9 .^{\circ}$ anos, jovens com a idade variando entre 12 e 14 anos, momento circunstancial vivido por interações sociais mais diversificadas e dotadas de muitas outras fontes de informação (como o acesso à TV e à Internet) que permitem o exercício imaginativo de projeção para a vida futura. ${ }^{22}$

Feitas por meio de redações, as autobiografias dos jovens evidenciam o exercício da imaginação sobre o futuro mediado por suas relações com os outros, desde o nascimento até a rotina vivida pela escola, porque inseridos em um processo de

22 Ao contrário das crianças mais novas, mais centradas sobre si mesmas, como mostrou Christina Toren $(2010)$. 
construção, manutenção e modificação de significados da experiência coletiva no bairro. Sob esse prisma, a posição centrada em si mesma, trazida pelo gênero autobiografia, é relativizada pelo nascimento, entrada no movimento da vida, e pela interação com os pais, parentes próximos, professores e amigos.

Em todas as redações o ponto de partida é a data do nascimento, mas as circunstâncias que envolveram o nascimento identificam interações existentes para o acolhimento deles. Por exemplo: "a mãe ficou contente com a gravidez" [Ana]; "Ela [a mãe], contou-me que no dia do meu nascimento estava em casa. Meu pai estava cansado e no momento das contrações ele estava dormindo..." [Everton]; "Minha mãe estava ansiosa com a minha chegada. Meu pai estava viajando e não acreditou que eu era uma menininha [...]" [Gisele]. As circunstâncias do nascimento indicam ainda a entrada no convívio com irmãos e nas interações em termos hierárquicos pela ordem do nascimento. Dizer com quem moram (normalmente com os pais), quantos irmãos têm, quantos morreram, se é mais velho ou mais novo é inseparável da apresentação de si e da própria identidade profundamente relacional.

As condições vividas pelos moradores no bairro são elaboradas pelos jovens no modo como compreendem a realidade cotidiana por meio da sua rotina. Frequentar a escola faz parte dessa rotina, ao lado das brincadeiras com os amigos e dos jogos na Internet, e da ajuda nos afazeres domésticos, principalmente no caso das meninas. A rotina vivida é um continuum do trabalho dos pais e dos adultos e não aparece como um contraponto entre um mundo cotidiano, íntimo, e um mundo público. Assim, quando falam dos pais, falam sobretudo dos meios de sobrevivência. Falar da sobrevivência é falar mais do trabalho do que da profissão. Isto porque falar do trabalho expressa as formas de cuidado com eles e com os outros: "minha mãe trabalha, meu pai não", "minha mãe é dona de casa". O tipo de ocupação exercida pelos pais não é explicitado, mas eles são qualificados como "trabalhador", "guerreiro", "batalhador". Tais categorias talvez indiquem o significado problemático que o trabalho pode ter no contexto de circulação de mercadorias na fronteira, embora alguns alunos indiquem a profissão dos pais como dona de casa, secretário, marceneiro, catador de lixo, etc.

Finalmente, como o exercício imaginativo desses jovens - que não se veem velhos o suficiente para falarem de si mesmos, mas não tão crianças que não possam falar de um passado de "quando eram pequenos" - é mediado por suas interações com os outros, a projeção do futuro é também um exercício de compreensão das pessoas e das interações sociais no bairro. Assim, tal como para os seus pais, o trabalho é a realização de si mesmos como adultos no futuro, mas, diferentes deles, querem ser advogados, policiais, engenheiros ou "professora para ajudar as crianças a ser alguém na vida" [Amanda]. "Ser alguém na vida" é uma categoria recorrente entre os jovens alunos e parece indicar tanto a capacidade de manter a própria sobrevivência quanto ter uma profissão especializada, capaz de cuidar e assegurar as relações de parentesco próximas. 
Daí a importância da escola vista quase como um único meio de formação profissional e de ascensão social. Algo interessante a ser pensado mais detidamente é a recorrência do sonho de ser advogado, que pode ser interpretado como uma profissão necessária para defesa dos direitos em um bairro em que o legítimo e o ilegal se confundem pelo comércio fronteiriço. As atividades de transportar mercadorias além da cota permitida ou proibidas, embora sejam um trabalho ilegal, são vistas como legítimas, condição existencial que insere muitos em uma zona de indeterminação em que a cidadania brasileira é, no mesmo movimento, reconhecida mas colocada em suspensão quando flagrados pelo envolvimento com essas atividades ilícitas, crimes caracterizados como contrabando e descaminho. Outras interpretações possíveis são que o sonho de ser advogado pode ser, em parte, devido à vontade de ingressar em uma carreira considerada prestigiada por altos cargos e privilégios no Brasil atual, às expectativas trazidas pelas ressonâncias de um debate intensificado no país a respeito dos direitos das minorias e à visibilidade crescente do Direito nas investigações da corrupção na política. Nesse sentido, a imaginação sobre o futuro explicita o processo pelo qual o significado de "ser alguém na vida" está em transformação nas mesmas atividades em que eles se mantêm, como filhos de "trabalhadores", "batalhadores" e "guerreiros".

Se as autobiografias evidenciaram a experiência dos alunos mediada por suas relações com os outros, dentro e fora da escola, o gênero teatro, ao incluir outros gêneros de discurso em sua preparação e ao encenar a história do bairro e da escola, reproduziu a totalidade da experiência etnográfica permitida pela inflexão trazida pela proposição e realização do Projeto Memória. A professora e os alunos dos primeiros anos do ensino médio escreveram juntos e encenaram um texto dramático para contar a história do bairro Cidade Nova, a ser apresentado na "Semana Interativa". A Semana Interativa é um evento importante, instituído pelo calendário escolar regular, quando a escola interrompe a sua rotina para interagir como os pais e moradores mostrando o que se vive e o que se faz na escola. Todas as salas de aulas ficam abertas nos três turnos de funcionamento com a exposição de diferentes tipos de trabalhos feitos por alunos. $\mathrm{Na}$ Semana Interativa do ano letivo em que ocorreu o Projeto Memória, foram expostos os cadernos de receitas, as cartas convites e cartas de agradecimento, o livreto da literatura de cordel, as fotografias antigas e recentes e os jornais do bairro, como também vídeos com as gravações das entrevistas e das biografias dos moradores. Um desses vídeos, com a biografia de um dos primeiros moradores feita por uma das alunas do $8 .^{\circ}$ ano, Ana Gabriela Dias, foi publicado pelo blogue CNI (Cidade Nova Informa), compartilhado no YouTube. ${ }^{23}$

23 Ana Gabriela Dias, 2012, "Biografia Morador Moisés do Bairro Cidade Nova - Parte II, Colégio Estadual Ipê Roxo, CNI”, disponível em <https://www.youtube.com/watch?v=1ZwQ14UZ0lU> (última consulta em janeiro de 2016). 
À medida que trabalhavam com a parte técnica de montagem da peça compreendendo melhor os elementos necessários para a encenação, com a colaboração de uma estagiária, foi iniciada a escrita. Para a escrita da peça, todos os dados das pesquisas do Projeto Memória foram utilizados, como as entrevistas, relatos orais e escritos dos moradores, além dos jornais do bairro e da cidade, de documentos oficiais da Cohafoz (Companhia de Habitação de Foz do Iguaçu). Utilizou-se também, como fonte, um documentário sobre as Cataratas do Iguaçu, em que se destacavam os moradores mais antigos. Durante a escrita, a professora, há 11 anos na escola, utilizou uma linguagem mais formal, mas os alunos levantaram as seguintes perguntas: "Professora, os moradores daqui não falam assim não, eles não tiveram escolaridade; nós, os filhos, que estamos estudando, é que falamos assim e se temos que representar a voz do povo do Cidade Nova, essa voz do texto não se parece com eles". O texto foi modificado várias vezes, o que rendeu noites de reescritas, discussões divertidas, e resultou na apresentação da peça, encenada nos três turnos - matutino, vespertino e noturno - do dia 28 de agosto de 2012, na Semana Interativa Comunidade Escola. O poema abaixo compõe o final da peça e narra a escola e o bairro como conquistas de um processo de luta simbólica e política:

"Em cada consciência, uma lembrança.

Cidade Nova, um sonho, uma esperança, uma nova chance...

A hora não é de sofrer, não deixa a tristeza saber.

A vida ensina, a escola da vida foi assim.

Sonhos não envelhecem.

Homens que aqui ocuparam se resumiam em sonhos.

O sonho da casa própria!

Um passo atrás do outro, um tijolo que se erguia, uma mão amiga

Uma gente querida, numa nova vila, vida, paisagem.

Cidade Nova, memória viva hoje e sempre!" [Patrícia de Souza, professora]

Como a imagem de um fractal, em si mesmo parte que reproduz todas as partes do todo, impedindo uma diferenciação entre a parte e o todo pela autossimilaridade, a encenação da peça expôs dupla e sinteticamente o cenário de luta pela urbanização e pela construção da escola como um acontecimento publicamente reconhecido, assim tornado explícito e sem nenhum subentendido. A política local emergiu nas encenações das reuniões em pequenos grupos no bairro, em assembleias de todos os moradores e de seus líderes com os representantes do poder público em torno das reivindicações do bairro, mas incluiu falas dos atores sobre o idealismo, a capacidade altruísta e o compromisso dos moradores. Digno de interesse é o simbolismo da "memória do bairro" feito pelo jornal escrito: a passagem do tempo transcorrido era encenada com a leitura em voz alta das manchetes dos jornais da época enquanto o cenário ia sendo mudado. 
A peça do teatro foi a forma sintética de totalizar a história do bairro e da escola, pela condensação de diversos gêneros de discursos usados na escrita do texto, pela encenação de acontecimentos publicamente reconhecidos e pela diluição dos limites entre a escola e o bairro. Entendido como práticas efetivas de aprendizagem, o movimento dessa experiência deu-se pela abertura não só física, mas simbólica dos limites da escola para os moradores do bairro. Porém, foi o movimento inverso, da diluição dos limites da escola em direção ao bairro que construiu um evento particular e aglutinador, ao solidificar essa totalidade da experiência etnográfica do Projeto Memória: a pesquisa de campo. Os moradores e os pais foram convidados para um encontro, quando os alunos fariam a realização das entrevistas, como se verá a seguir.

Em uma manhã de inverno gelada, úmida e cinzenta, foi feita uma caminhada dos alunos, professores e pesquisadores, para o encontro com os pais e outros moradores na chácara localizada no bairro e cedida pelo proprietário, frequentemente utilizada pelos moradores para momentos de lazer, sempre com autorização, e denominada pelos alunos como "chacrinha".

As entrevistas foram marcadas com antecedência com os moradores mais antigos e com aqueles que tiveram um papel de liderança nas reivindicações por melhorias no bairro. Elas foram preparadas antes e o dia do encontro é que foi designado como o "dia da pesquisa de campo". Esse foi o evento aglutinador de condensação dessa experiência coletiva, podendo ser entendido como um ritual de conversão simbólica, ${ }^{24}$ de apropriação moral e política do bairro, que, em um movimento inverso, "saiu" da escola para se espraiar no bairro e alcançar a "chacrinha". Desde a saída da escola havia um clima festivo, dado pelos balóes coloridos. Depois de uns mil metros de caminhada e chegando à "chacrinha", faixas de agradecimento público foram estendidas. Estar na "chacrinha" foi uma celebração, um momento festivo. Ela se tornou o espaço da vivência de um momento extraordinário de transformação da rotina escolar em que se exaltou a lembrança da luta pela apropriação do bairro, das conquistas obtidas, como a escola e os serviços de infraestrutura urbana.

A caminhada forneceu um sentimento de comunidade política complexa, invocando diferentes laços relacionais, mas igualmente incorporando os efeitos contraditórios da desapropriação anterior, presente pela lembrança da "luta" e dos "sofrimentos" dos moradores do bairro. Simultaneamente, foi outra manifestação do espaço interativo tornado possível pela articulação entre as políticas públicas nacionais, corporificadas no programa Observatório da Educação, e as práticas e os saberes, tanto escolares quanto locais. Trata-se de uma forma de conhecimento vivido como "comunidade de prática" em que moradores,

24 Utilizo aqui as análises dos rituais vinculados a eventos propostas por Mariza Peirano (2001). Trata-se de eventos reconhecidos por seus participantes como fenômenos especiais, dotados de significado político. 
alunos, pais, professores, pesquisadores e participantes se deram a ver e, como diria Durkheim (2000), se recriaram.

Foi também uma experiência estética, no sentido de Dewey (2010), de enriquecer a experiência imediata, tornando-a repleta de significados. Isto é, uma experiência singular que se tornou manifesta e claramente perceptível na caminhada ritual e no encontro festivo na chacrinha, nos quais houve a revelação de todos como comunidade específica, como pessoas que interagem e dialogam entre si. O "(des)entranhamento" da escola como inseparável da conquista dos pais/moradores em suas disputas com o poder político local, propiciado pela experiência da aprendizagem como "comunidade de prática", evidenciou, assim, a aprendizagem como parte da intervenção social e política no presente vivido na escola e no bairro.

\section{CONSIDERAÇÕES FINAIS}

Do ponto de vista da experiência coletiva vivida na escola, podemos enfatizar três considerações importantes, descritas a seguir.

A primeira, retomando a ideia de Roy Wagner (2010), é que nossos modelos analógicos para a interpretação são eles mesmos interpretados no processo de experiência coletiva, com claras implicações para todos os envolvidos, evidenciando uma forma de conhecimento muito mais baseada na participação e no aprendizado conjunto do que na compreensão. Como consequência, se nossa inserção como pesquisadores nos tornou igualmente gestores e porta-vozes de um programa nacional de educação, ao nos confrontarmos com outros modos de enfrentar o fracasso escolar e com as particularidades da escola e do bairro, tornamo-nos interlocutores entre professores, alunos e moradores, compartilhando a mesma situação. Gradualmente, no curso da experiência etnográfica, tornou-se explícito o elo que nos transformou em uma "comunidade de conhecedores", pelo atravessamento das políticas educacionais do Estado unindo a universidade à escola, pela imersão no contexto histórico e social do bairro na cidade e pela visibilidade ontológica da política na aprendizagem, a partir da efetiva e ativa participação dos alunos e de todos.

A segunda, um desdobramento da primeira, é que uma antropologia cognitiva da aprendizagem implica entender essa questão como um problema relacional na vida social, cujos participantes interagem uns com os outros como condição e precondição de sua existência. Na terminologia de Jean Lave (1988), a aprendizagem é "compreensão pela prática", não apenas a transmissão de conhecimento feita por um processo de socialização e inculcação cultural. Como tentei evidenciar, a aprendizagem é situada, está embebida na prática e resulta de uma interação social de componentes que incorporam as desigualdades sociais, os processos classificatórios e os comportamentos adquiridos. Disso resulta que a proposição do Projeto Memória gerou um processo 
de inflexão fundamental, pois incorporou esses componentes, visíveis nos "problemas sociais", categoria que sintetiza, no campo etnográfico, as diversas causas para os baixos índices de avaliação e elevada evasão e reprovação dos alunos: a localização espacial e simbólica do bairro, identificado como pobre, "perigoso", marcado pelo passado vivido em favela e pelas atividades ilícitas, e da própria escola, marginalizada por essa localização do bairro na cidade. Esses "problemas sociais" incorporados deixaram de ser obstáculos e se converteram em princípios geradores de uma aprendizagem situada, ao reunir um modo de pertencimento social singular e abranger formas de interação e de historicização como parte do presente social, cultural e político vivido na escola e no bairro como um todo inseparável. Embora a aprendizagem tenha tido como tema central a memória do bairro, os vários "gêneros discursivos" (Bakhtin 2003) foram praticados por várias disciplinas dos professores participantes do projeto (língua portuguesa, matemática, geografia, inglês e história). Todos os gêneros discursivos implicaram a leitura, a compreensão e a estrutura composicional que não só permitiram uma análise linguística e o desenvolvimento de práticas pedagógicas de interesse dos pesquisadores sociolinguistas, mas, sobretudo, permitiram aos participantes constituir-se como grupo pelas relações de interação aí aprofundadas. Isto é, foi esse processo que possibilitou a efetividade da aprendizagem de forma social e culturalmente situada na prática cotidiana, pela coconstrução do conhecimento, por meio dos gêneros discursivos (Pires-Santos et al. 2015). Tornou-se, assim, manifesta a dissolução de dicotomias entre aprender e fazer, entre a diferença cultural e a desigualdade social, entre criança e adulto, professor e aluno, forma e conteúdo da aprendizagem. Por isso, o conhecimento é uma relação entre comunidades de prática e participação em prática.

A terceira consideração importante é que essa experiência se constituiu como a emergência de espaços intermediários e interativos, situados entre as formas institucionais incorporadas pelas políticas públicas nacionais e a prática local dos muitos agentes envolvidos, vivenciada como um surpreendente estranhamento que permitiu ver o que não se via. Tal movimento tornou-se possível por um desentranhamento momentâneo da escola que, de escola do bairro, passou a ser vista com outro significado, como inseparável das conquistas dos moradores em suas disputas com o poder político local. O resultado foi o "desentranhamento" da escola de si mesma para abranger o bairro e a cidade e cuja razão de ser foi fruto de uma conquista política e simbólica frente ao poder público local. Estruturante de práticas e saberes, a aprendizagem implicou o modo de pertencimento do bairro e evidenciou múltiplos cruzamentos de experiências diferentes e compartilháveis entre todos os envolvidos. 


\section{BIBLIOGRAFIA}

ABU-LUGHOD, Lila, 1999, "Comments" (on Christoph Brumann's "Writing for culture: why a successful concept should not be discarded"), Current Anthropology, 40 (sup.): 13-15.

AlbuQUerque, Jose Lindomar Coelho, 2010, As Dinâmicas das Fronteiras: Os Brasiguaios entre o Brasil e o Paraguai. São Paulo, Annablume.

BAKHTIN, Mikhail, 2003, Estética da Criação Verbal. São Paulo, Martins Fontes.

BOMENY, Helena, 2001, Darcy Ribeiro: Sociologia de Um Indisciplinado. Belo Horizonte, Editora UFMG.

BOURDIEU, Pierre, 1979, La distinction: critique sociale du jugement. Paris, Les Editions de Minuit.

BOURdieu, Pierre, 1982, A Economia das Trocas Simbólicas. São Paulo, Perspectiva.

CARDIN, Eric Gustavo, 2011 , "Ação racional e cotidiano: notas para o estudo dos trabalhadores da Tríplice Fronteira, em M.E.P. Santos e R.C.M. Silva (orgs.), Cenários em Perspectiva: Diversidades na Tríplice Fronteira. Cascavel, Edunioeste, 121-139.

CASTRO, Eduardo Viveiros de, 2002, “O conceito de sociedade em antropologia”, em E. V. de Castro, A Inconstância da Alma Selvagem. São Paulo, Cosac Naify, 297-316.

CATTA, Luiz Eduardo Pena, 2011, "Pobreza e marginalidade na Tríplice Fronteira", em M. E.P. Santos e R.C.M. Silva (orgs.), Cenários em Perspectiva: Diversidades na Tríplice Fronteira. Cascavel, Edunioeste, 91-120.

COHN, Clarice, 2000, "Crescendo como um Xikrin: uma análise da infância e do desenvolvimento infantil entre os Kayapó-Xikrin do Bacajá”, Revista de Antropologia, 43 (2): 195-222, disponível em < http://www.scielo.br/scielo.php?script=sci_arttext\&pid=S0034-770 12 $000000200009 \& \operatorname{lng}=\mathrm{en} \& \operatorname{lng}=\mathrm{pt}>$ (última consulta em fevereiro de 2016).

COHN, Clarice, 2005, Antropologia da Criança. Rio de Janeiro, Jorge Zahar Editor.

DAUSTER, Tânia, 2004, "Entre a antropologia e a educação: a produção de um diálogo imprescindível e de um conhecimento híbrido", Ilha, 6 (1-2): 197-207.

DEWEY, John, 2010, Arte como Experiência. São Paulo, Martins Fontes.

DURKHEIM, Émile, 2000, As Formas Elementares da Vida Religiosa. São Paulo, Martins Fontes.

FOUCAUlT, Michel, 1988, Microfísica do Poder. Rio de Janeiro, Graal.

FOUCAUlT, Michel, 1999, Vigiar e Punir: Nascimento da Prisão. Rio de Janeiro, Vozes.

GUSMÃO, Neusa Maria Mendes de, 1997, "Antropologia e educação: origens de um diálogo", Cadernos CEDES, 18 (43): 8-25, disponível em < http://www.scielo.br/scielo.php? script $=$ sci_arttext\&pid $=$ S0101-32621997000200002\&lng $=$ en\&nrm $=$ iso $>\quad$ (última consulta em janeiro de 2016).

INGOLD, Tim, 1991, "Become persons: consciousness and sociality in human evolution", Cultural Dynamics, 4 (3): 355-378.

INGOLD, Tim, 1993, “Technology, language, intelligence: a reconsideration of basic concepts”, em K. R. Gibson e T. Ingold (orgs.), Tools, Language and Cognition in Human Evolution. Cambridge, Cambridge University Press, 449-472.

INGOLD, Tim, 2002, "Culture, perception and cognition", em T. Ingold, The Perception of the Environment: Essays on Livehood, Dwelling and Skill. Londres, Routledge, 157-171.

LAHIRE, Bernard, 2003, "Crenças coletivas e desigualdades culturais", Educação e Sociedade; 24 (84): 983-995. 
LAVE, Jean, 1988, Cognition in Practice: Mind, Mathematics and Culture in Everyday Life. Cambridge, Cambridge University Press.

LAVE, Jean, 1996, "Teaching, as learning, in practice", Mind, Culture and Activity, 3: 149$-164$.

LAVE, Jean, 2011 , "Hacia una ontología social del aprendizaje", Revista de Estudios Sociales, 40: $12-22$.

LAVE, Jean, e Etienne WENGER, 1991, Situated Learning: Legitimate Peripheral Participation. Cambridge, Cambridge University Press.

LOPES, L.P. Moita, e R.H.R. ROJO, 2004, Avaliação Crítica e Propositiva dos PCNEM-PCNEM+: Áreas de Linguagens, Códigos e Suas Tecnologias. Brasília, DF, MEC/SEMTEC.

McDERMOTT, Ray, e Hervé VARENNE, 1995, "Culture as disability", Anthropology and Education Quarterly, 26: 323-348, disponível em < http://serendip.brynmawr.edu/sci_cult/cul turedisability.html $>$ (última consulta em janeiro de 2016).

OLIVEIRA, Dalila Andrade, 2011 , "Das políticas de governo à política de estado: reflexões sobre a atual agenda educacional brasileira”, Educação e Sociedade, 32 (115): 323-337, disponível em < http://www.cedes.unicamp.br > (última consulta em janeiro de 2016).

ORTNER, Sherry B., 1984, "Theory in anthropology since the sixties", Comparative Studies in Society and History, 26 (1): 167-173.

PEIRANO, Mariza, 2001, O Dito e o Feito: Ensaios de Antropologia dos Rituais. Rio de Janeiro, Relume Dumará.

PIRES, Flávia, 2010, "O que as crianças podem fazer pela antropologia?", Horizontes Antropológicos, 16 (34): 137-157, disponível em < http://www.scielo.br/scielo.php?script=sci_ arttext\&pid=S0104-71832010000200007\&lng=en\&nrm =iso $>$ (última consulta em janeiro de 2016).

PIRES-SANTOS, Maria Elena, et al., 2015, “ 'Vendo o que não se enxergava': condições epistemológicas para construção de conhecimento coletivo e reflexivo da língua(gem) em contexto escolar", DELTA: Documentação de Estudos em Lingüística Teórica e Aplicada, 31 (número especial): 35-65, disponível em < http://www.scielo.br/scielo.php?script=sci_ arttext\&pid=S0102-44502015000300004\&lng=pt\&nrm =iso > (última consulta em janeiro de 2016).

PPP - Projeto Político Pedagógico, 2002, elaborado pelos professores do Colégio Ipê Roxo. Foz do Iguaçu, mimeo.

QVORTRUP, Jens, 2010, "A infância enquanto categoria estrutural", Educação e Pesquisa, 36 (2): 631-644, disponível em < http://www.scielo.br/scielo.php?script=sci_arttext\&pid $=$ S1517-97022010000200014\&lng =en\&nrm =iso\&tlng=pt $>$ (última consulta em janeiro de 2016).

ROBERTSON, Susan, e Antonio VERGER, 2012, "A origem das parcerias público-privada na governança global da educação", Educação e Sociedade, 33 (121): 1133-1156, disponível em <http://www.scielo.br/scielo.php?script=sci_arttext\&pid=S0101-7330 $2012000400012 \& \operatorname{lng}=\mathrm{en} \& n r m=$ iso\&tlng $=\mathrm{pt}>($ última consulta em janeiro de 2016).

SANTOS, Maria Elena P. Pires, 2010, Observatório da Educação. Núcleo de Pesquisa/Extensão: Formação Continuada em Leitura, Escrita e Oralidade. Foz do Iguaçu, mimeo.

SANTOS, Maria Elena Pires, 2012, "Deslocamentos transfronteiriços e as narrativas de identidades”, em M.E. P. Santos e R.C.M. Silva (orgs), Interdisciplinaridade e Fronteiras: Movimentos, Identidades e Configurações. Cascavel, Edunioeste, 147-173. 
SILVA, Regina Coeli Machado e, 2011 , "Juventudes e dramas de moralidade: dissonâncias nas práticas de leitura e de escrita em uma escola de Foz do Iguaçu”, relatório CNPq, Foz do Iguaçu, mimeo.

SOUZA, Silvana Aparecida de, 2001, Gestão Escolar Compartilhada: Democracia ou Descompromisso? São Paulo, Xamã Editora.

SOUZA, Silvana Aparecida de, 2009, "Formas renovadas de privatização da educação no Brasil: o trabalho voluntário e a responsabilidade social da empresa (RSE)", Educação: Teoria e Prática, 19 (32): 73-88, disponível em < http://www.periodicos.rc.biblioteca. unesp.br/index.php/educacao/article/view/2598/2443 > (última consulta em janeiro de 2016).

SOUZA, Silvana Aparecida de, 2013, Educação, Trabalho Voluntário e "Responsabilidade Social". São Paulo, Xamã Editora.

STOLCKE, Verena, 1995, "Talking culture: new boundaries, new rhetorics of exclusion in Europe”, Current Anthropology, 36: 1-24.

STRATHERN, Marilyn, 2014, "O conceito de sociedade está teoricamente obsoleto?", em Marilyn Strathern, O Efeito Etnográfico e Outros Ensaios. São Paulo, Cosac Naify, 23 1-240.

TOREN, Christina, 1993, "Making history: the significance of childhood cognition for a comparative anthropology of mind", Man, 28: 461-478.

TOREN, Christina, 2003, "Becoming a Christian in Fiji: an ethnographic study of ontogeny", The Journal of the Royal Anthropological Institute, 9 (4): 709-727, disponível em < http://www.jstor.org/stable/3134707 > (última consulta em janeiro de 2016).

TOREN, Christina, 2010, "A matéria da imaginação: o que podemos aprender com as idéias das crianças fijianas sobre suas vidas como adultos", Horizontes Antropológicos, 34: 19-48.

TOREN, Christina, 2012, "Antropologia e psicologia", Revista Brasileira de Ciências Sociais, 27 (80): 21-36, disponível em < http://www.scielo.br/pdf/rbcsoc/v27n80/v27n80a02. pdf $>$ (última consulta em janeiro de 2016).

WAGNER, Roy, 2010, A Invenção da Cultura. Rio de Janeiro, Cosac Naify. 